\title{
Transfer Factors in Escherichia coli with Particular Regard to Their Incidence in Enteropathogenic Strains
}

\author{
By H. WILLIAMS SMITH AND MARGARET A. LINGGOOD \\ The Animal Health Trust, Stock, Essex
}

(Accepted for publication 4 May 1970)

\begin{abstract}
SUMMARY
Strains of Escherichia coli were isolated whose resistance to ampicillin (Ap), tetracyclines $(\mathrm{Tc})$ or streptomycin and sulphonamides $(\mathrm{SmSu})$ or whose production of colicine (Col) or $\alpha$-haemolysin (Hly) could not be transmitted to E. coli $\mathrm{K} \mathrm{I} 2 \mathrm{~F}^{-}$. Determinants controlling these characters (except Ap), could be mobilized in some of them after infection with transfer factors. Of 60 strains of $E$. coli isolated from the faeces of healthy pigs, cattle and human beings and selected because they did not possess $\mathrm{R}$ factors and did not produce colicine, $\alpha$-haemolysin, porcine enterotoxin (Ent) or K 88 antigen (transmissible characteristics), $20(33 \%)$ contained transfer factors that could mobilize determinants from one or more of nine determinant donor strains; 8 contained at least two transfer factors, one $f^{-}$and the other $f^{+}$. The nine determinant donor strains contained Tc, SmSu, Col or Hly determinants; some were wild strains and others were obtained from interrupted mating experiments in which $E$. coli $\mathrm{KI}_{2} 2 \mathrm{~F}^{-}$was the recipient strain. The ability of a transfer factor to mobilize a determinant was not simply a function of the transfer factor and the determinant but was strain-dependent. Positive results were obtained most frequently when transfer was between strains of $\mathrm{K} I 2$. Transfer factors that could mobilize determinants in determinant donor strains were found in all except one of 78 porcine enterotoxigenic strains of $E$. coli selected because they did not possess R factors or transmissible colicine. Nearly all of them produced $\alpha$-haemolysin and over half of them K 88 antigen. On the evidence available, the high incidence of transfer factors in these strains suggests that enterotoxin production in all of them was controlled by transmissible plasmids and that the genetic determinants controlling $\alpha$-haemolysin production in some of them might be chromosomal. The linkage between Ent and the factor responsible for its transfer was not always close. Despite a previous statement to the contrary (Smith \& Halls, I968), this transfer factor was $f^{-}$; both $f^{-}$and $f^{+}$factors could transfer Hly. No close association between the plasmids controlling the five characteristics Neo (neomycin resistance), Ent, Col, Hly and K 88 was apparent in mating experiments using as donor a porcine strain of E. coli carrying all five transmissible plasmids. Transfer factors were found in I5 of $2 \mathrm{I}$ human enteropathogenic strains and in one of five sheep enteropathogenic strains; none of these 26 strains possessed characteristics known to be transmissible.
\end{abstract}

\section{INTRODUCTION}

Most strains of Escherichia coli that cause diarrhoea and oedema disease in pigs produce $\alpha$-haemolysin, a property also possessed by a small proportion of the nonpathogenic strains that inhabit the alimentary tract of man and domestic animals (Smith, 1963). Smith \& Halls (1967a) found that in some strains of E. coli the pro- 
duction of this haemolysin was controlled by a transmissible plasmid (Hly). A transmissible plasmid (Ent) was also shown to control enterotoxin production in some porcine enteropathogenic strains (Smith \& Halls, 1968). Owing to the absence of sensitive selection procedures, Hly and, particularly, Ent transmission can only be demonstrated when it occurs at a high rate, very much higher than that required to demonstrate $\mathrm{R}$ factor transfer. This may account for the failure of Smith \& Halls to detect transmission of Hly and Ent from the majority of strains they examined. Alternatively, Hly and Ent existed in these strains in a nontransmissible state.

To elucidate the situation the incidence of the genetic elements responsible for plasmid transmission, i.e. the sex factors, conjugation factors or transfer factors, in porcine enteropathogenic strains and in haemolytic nonpathogenic strains of Escherichia coli was examined. To do this, it was first necessary to find strains possessing mobilizable but initially nontransmissible determinants. Determinant mobilization tests (Anderson, 1965a, $b$; Anderson \& Lewis, 1965) were employed for detecting strains containing transfer factors. The mobilizable determinants employed included those controlling antibiotic resistance since the transfer of such determinants can easily be detected. In addition, strains of $E$. coli enteropathogenic for human babies, calves and lambs were also examined for transfer factors.

Throughout this paper, a genetic element described as mobilizable is one that can only be transferred after its host has been infected with a transfer factor. A transmissible genetic element is one whose host possesses such a transfer factor.

\section{METHODS}

The identification of nontransmissible characters in strains of Escherichia coli. This was exactly as described by Smith \& Gyles (1970).

The identification of strains of Escherichia coli containing mobilizable determinants. This was performed by a modification of the method of Anderson (I965a,b) and Anderson \& Lewis (1965). Strains whose $\mathrm{Hly}, \mathrm{Col}$ or antibiotic resistance could not be transferred directly to $E$. coli K I $2 \mathrm{~F}^{-}$were inoculated into nutrient broth with $E$. coli $\mathrm{K} 12 \mathrm{~F}^{+}$and incubated at $37^{\circ}$ for $24 \mathrm{~h}$. This mixed culture was then subcultured together with the nalidixic acid-resistant mutant of the $l a c^{-} E$. coli $\mathrm{K}$ I $2 \mathrm{~F}^{-}$and incubated for another $24 \mathrm{~h}$. The final culture was then examined for determinant transfer to the $\mathrm{K} I 2 \mathrm{~F}^{-}$strain by the methods previously described. If transfer did not occur, the experiment was repeated using strains of $E$. coli containing transfer factors other than $\mathrm{F}$ in place of the $\mathrm{K} \mathrm{I}_{2} \mathrm{~F}^{+}$strain. Determinants that could be transferred by this technique but not by the usual mixed-culture technique are referred to subsequently as mobilizable and the strains containing them as determinant donor strains.

The identification of strains of Escherichia coli containing transfer factors. This was performed in the same way as the experiments designed to identify strains containing mobilizable determinants except that strains known to contain mobilizable Hly, Col or antibiotic resistance determinants were now employed as determinant donor strains, and the strain under test for carriage of a transfer factor lacked the respective property, i.e. was $\mathrm{Hly}^{-}$, $\mathrm{Col}^{-}$or $\mathrm{R}^{-}$. Transfer of the character concerned to the $\mathrm{K} \mathrm{I} 2$ $F^{-}$recipient strain indicated that the strain under the test contained a transfer factor.

Fertility-inhibiting $(f i)$ character of transfer factors. This was assessed by transmitting a determinant by means of the transfer factor under the test into an $\mathrm{F}^{+}$strain 
of Escherichia coli $\mathrm{K} 12$ and then examining for susceptibility to lysis by the F-specific phage MS 2 (Davis, Strauss \& Sinsheimer, 196I).

The detection of enterotoxin production by porcine strains of Escherichia coli. This was achieved by injecting broth cultures into ligated segments of pig small intestine according to the methods of Smith \& Halls (1967b).

\section{RESULTS}

The incidence of strains of Escherichia coli possessing mobilizable determinants

The incidence of strains of Escherichia coli whose haemolysin production and antibiotic resistance could not be transferred to $E$. coli $\mathrm{K} \mathrm{I} 2 \mathrm{~F}^{-}$in mixed culture is shown in Table I. Most of the strains whose tetracycline, streptomycin and sulphonamide or ampicillin resistance was nontransmissible were resistant to these antibiotics only. Table I also shows the number of strains in which the genetic determinants for these characters could be mobilized by means of infection with $\mathrm{F}$ or other transfer factors. The Col as well as SmSu was mobilized in one strain, B I65; the colicine was identified by Professor Fredericq of the University of Liége as E I. Of the four strains with mobilizable Hly, two actually contained transfer factors that could mobilize SmSu but not, of course, Hly; neither strain was used in subsequent studies. None of the other strains with mobilizable determinants was shown to possess transfer factors that could mobilize other determinants.

\section{Table I. The incidence of wild strains of Escherichia coli possessing} nontransmissible but mobilizable determinants

$\begin{array}{cccc}\text { Determinant } & \begin{array}{c}\text { No. of } \\ \text { strains } \\ \text { possessing } \\ \text { this } \\ \text { determinant }\end{array} & \begin{array}{c}\text { No. in } \\ \text { which it } \\ \text { was non- } \\ \text { transmissible }\end{array} & \begin{array}{c}\text { No. in } \\ \text { which it } \\ \text { was } \\ \text { mobilizable }\end{array} \\ \text { Tc } & 60 & \text { 10 } & 5 \\ \text { SmSu } & 7 \text { I } & 20 & 6 \\ \text { Ap } & 25 & 14 & 0 \\ \text { Cm } & 2 \text { I } & 0 & 0 \\ \text { Neo } & 8 & 0 & 0 \\ \text { Hly } & 99 & 66 & 4\end{array}$

Tc, SmSu, Ap, $\mathrm{Cm}$ and Neo: resistance to tetracycline, streptomycin and sulphonamide, ampicillin, chloramphenicol and neomycin respectively. Hly: $\alpha$-haemolysin production.

Some of the wild strains with mobilizable determinants were infected with $\mathrm{F}$ and their determinants transferred to $\mathrm{KI} 2 \mathrm{~F}^{-}$. Matings between the resulting $\mathrm{KI}_{2} \mathrm{~F}^{+}$ strains and $\mathrm{KI} 2 \mathrm{~F}^{-}$were then performed and some $\mathrm{KI} 2$ strains were obtained that had received determinants but not $\mathrm{F}$ (Smith \& Gyles, 1970). This was an additional source of strains with mobilizable determinants.

On the basis of preliminary tests with strains of Escherichia coli known to contain transfer factors and the strains with mobilizable determinants, eight were chosen as determinant donor strains. Five were wild strains, B I65 $\mathrm{SmSu}^{+} \mathrm{Col}^{+}, \mathrm{H}$ I2 I SmSu $\mathrm{Tc}^{+}$, B I $50 \mathrm{SmSu}^{+}, \mathrm{HI} 20 \mathrm{Tc}^{+}$and P I02 $\mathrm{Hly}^{+}$. The remaining three, KI2 $\mathrm{F}^{-} \mathrm{SmSu}^{+}$(B I65) $\mathrm{Tc}^{+}$(H I2O), $\mathrm{KI}_{2} \mathrm{~F}^{-} \mathrm{SmSu}^{+}$(H I2I) and $\mathrm{KI}_{2} \mathrm{~F}^{-} \mathrm{Hly}^{+}$(P IO2), were $\mathrm{KI}_{2} \mathrm{~F}^{-}$strains into which determinants from some of the five wild strains had been introduced. The 
number in brackets indicates the strain from which the determinants originated. Unlike the other two $\mathrm{KI}_{2} \mathrm{~F}^{--}$strains, the loss of $\mathrm{F}$ from $\mathrm{K} \mathrm{I}_{2} \mathrm{~F}^{-} \mathrm{SmSu}^{+}$(в I65) $\mathrm{Tc}^{+}$ (H I 20) occurred spontaneously during laboratory cultivation. This set of eight strains was completed by the addition of an $\mathrm{SmSu}^{+}$strain of Salmonella typhimurium, RT 727, kindly provided by Dr E. S. Anderson of the Enteric Reference Laboratory, London, N.W.9.

The determinants possessed by seven of the nine determinant donor strains were transferred to Escherichia coli $\mathrm{K} \mathrm{I}_{2} \mathrm{~F}^{-}$by means of $\mathrm{F}$ and the susceptibility to visible lysis by MS 2 phage of 20 determinant-containing $\mathrm{K} I 2 \mathrm{~F}^{+}$colonies obtained from each mating was assessed; an $f^{-}$transfer factor had to be used to transfer the determinants from the remaining two strains, B I50 $\mathrm{SmSu}^{+}$and $\mathrm{RT} 727 \mathrm{SmSu}^{+}$, the recipient strain in their case being $\mathrm{K} 12 \mathrm{~F}^{+}$. All the colonies except those that had received determinants from $\mathrm{HI} 20 \mathrm{Tc}^{+}$and $\mathrm{KI}_{2} \mathrm{~F}^{-} \mathrm{SmSu}^{+}\left(\mathrm{BI}_{65}\right) \mathrm{Tc}^{+}$(HI20), a strain containing the Tc determinant of $\mathrm{HI} 20 \mathrm{Tc}^{+}$, were lysed by MS 2 . Only one of the $20 \mathrm{KI} 2$ colonies that had received Tc but not $\mathrm{SmSu}$ from K I2 $\mathrm{F}^{-} \mathrm{SmSu}^{+}$(в I65) $\mathrm{Tc}^{+}$(H I 20) and only three of the 20 colonies that had received $\mathrm{SmSu}$ but not Tc from this strain were lysed by MS 2 . When the experiments with $\mathrm{K} \mathrm{I}_{2} \mathrm{~F}^{-} \mathrm{SmSu}^{+}\left(\mathrm{B} \mathrm{I}_{65}\right) \mathrm{Tc}^{+}(\mathrm{H} \mathrm{I} 2 \mathrm{O})$ were repeated and antibiotic-sensitive instead of antibiotic-resistant colonies were tested, all but one of 40 of them were lysed by MS 2. Of the $20 \mathrm{~K} \mathrm{I} 2 \mathrm{~F}^{+}$colonies that had received Tc determinants from $\mathrm{H} \mathrm{I}_{20} \mathrm{Tc}^{+}$, $\mathrm{I} 8$ were lysed by $\mathrm{MS} 2$ and two were not. When cultures obtained from colonies of each type were mated with $\mathrm{K} I 2 \mathrm{~F}^{-}$, no obvious difference was noted in the rate at which Tc was transmitted. All of 20 colonies obtained from the mating in which the donor was susceptible to lysis by MS 2 were also susceptible to this phage; all 20 colonies obtained from the mating in which the donor was insusceptible, however, were also insusceptible. In view of the results obtained with $\mathrm{HI} 20 \mathrm{Tc}^{+}$and $\mathrm{KI} 2 \mathrm{~F}^{+}$ $\mathrm{SmSu}^{+}$(в I65) $\mathrm{Tc}^{+}$(H I 20) it was assumed that they possessed a transfer factor which, although unable to transfer or mobilize Tc, SmSu, Col or Hly, was able to inhibit the expression of $\mathrm{F}$. For this reason they were not used subsequently to assess the $f i$ character of transfer factors.

The incidence of transfer factors amongst strains of Escherichia coli isolated from the faeces of healthy pigs, cattle and human beings

The incidence of transfer factors in 60 strains of Escherichia coli, isolated from the faeces of healthy pigs, cattle and human beings, that could mobilize $\mathrm{SmSu}, \mathrm{Tc}, \mathrm{Col}$ or Hly from the nine determinant donor strains is illustrated in Table 2. All the mobilization tests necessary to complete this and subsequent tables were first performed once and, where considered necessary, those yielding negative results were then repeated several times before they were finally recorded as negative. During this repeat testing it was not unusual for some tests to yield positive results. The 60 strains tested were specially selected in that none of them were antibiotic-resistant or produced colicine, haemolysin, K 88 antigen, or in the case of pig strains, enterotoxin, characters that can be controlled by transmissible plasmids. In addition, none of them were latently infected with phages active against $\mathrm{K} I 2 \mathrm{~F}^{-}$. The pigs, cattle and human beings from which the strains had been isolated were all from different herds or households.

Approximately the same proportion of the pig, cattle and human strains were found to contain transfer factors, 30 to $40 \%$. There was great variation in the extent to which the different determinants in the donor strains were mobilized. For example, all 
20 strains found to contain transfer factors mobilizedSmSu from K I $2 \mathrm{~F}^{-} \mathrm{SmSu}^{+}$(H I 2 I) whereas only nine of them mobilized SmSu from в I50. Again, the Tc determinant in H I2I SmSu${ }^{+} \mathrm{Tc}^{+}$was mobilized by only one of the 20 strains whereas its $\mathrm{SmSu}$ determinant was mobilized by $\mathrm{I} 3$. Determinants were mobilized less frequently from wild strains than from $\mathrm{K} \mathrm{I} 2 \mathrm{~F}^{-}$strains into which their determinants had been introduced. For example, Hly was mobilized in $\mathrm{K} \mathrm{I}_{2} \mathrm{~F}^{-} \mathrm{Hly}^{+}$(P IO2) by ten strains but only four of them mobilized it from $\mathrm{P} 102 \mathrm{Hly}^{+}$itself. In the $\mathrm{K} \mathrm{I}_{2} \mathrm{~F}^{-}$determinant donor strains, Hly mobilization was detected less frequently than $\mathrm{R}$ factor mobilization, probably a reflexion of the comparatively poor methods available for selecting $\mathrm{Hly}^{+}$ organisms.

\section{Table 2. The incidence of transfer factors in strains of Escherichia coli isolated} from the faeces of healthy unrelated pigs, cattle and human beings

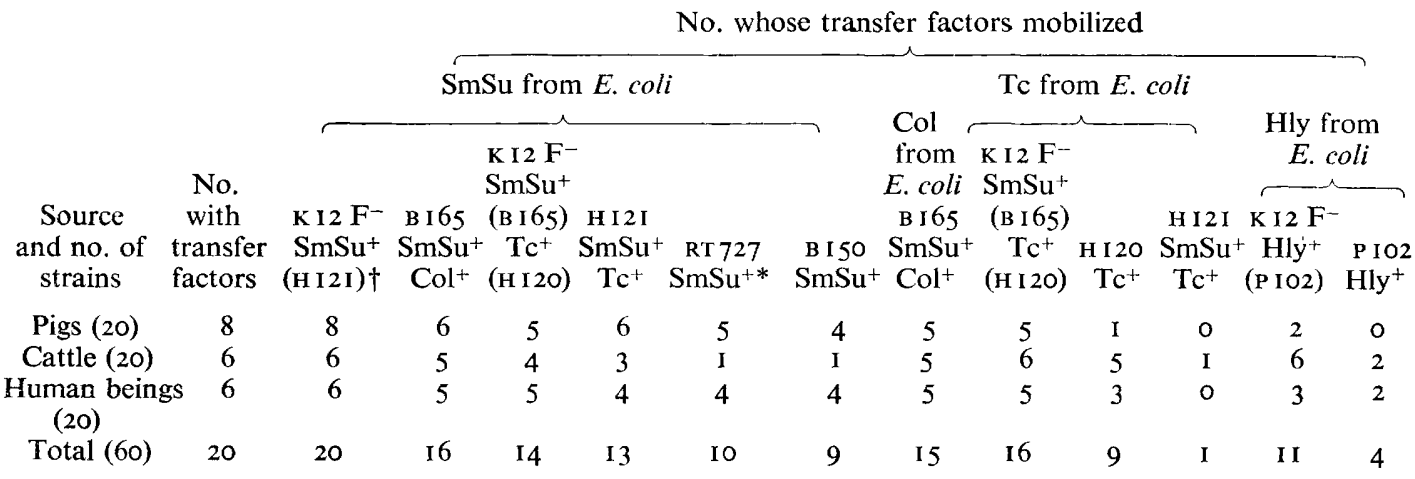

$\mathrm{Sm}, \mathrm{Su}, \mathrm{Tc}, \mathrm{Col}$ and $\mathrm{Hly}$ : determinants for streptomycin, sulphonamide and tetracycline resistance, and colicine and haemolysin production. $\mathrm{P}, \mathrm{B}$ and $\mathrm{H}$ : porcine, bovine and human respectively.

* Salmonella typhimurium not Escherichia coli.

$\dagger$ The symbols in parentheses indicate the strains from which the determinants originated.

The 20 strains possessing transfer factors are grouped together in Table 3 according to determinant mobilizing ability; it illustrates the great difference between some of the strains in this respect. Escherichia coli $\mathrm{K} \mathrm{I}_{2} \mathrm{~F}^{+}$and $\mathrm{K} \mathrm{I} 2 \mathrm{~F}^{-}$(P 275), a K I $2 \mathrm{~F}^{-}$strain into which had been introduced the transfer factor of one of these 20 strains, P 275, are included for comparison. $\mathrm{KI}_{2} \mathrm{~F}^{-}$(P275) was a better mobilizer than was P 275 ; its mobilizing ability, was, however, inferior to that of $\mathrm{K} \mathrm{I} 2 \mathrm{~F}^{+}$and of several of the other strains. On the basis of the $f$ tests, at least eight of the 20 strains contained two transfer factors, one $f^{+}$and the other $f_{i}^{-}$; these eight included five of the six bovine strains. There was no obvious indication that some determinants were always mobilized by $\mathrm{fi}^{+}$transfer factors and others by $\mathrm{fi}^{-}$ones. In the case of strains containing an $\mathrm{fi}^{+}$and a $f^{-}$transfer factor, it was sometimes difficult or even impossible to determine which one had been responsible for transferring a particular determinant because, in $f i$ tests, transfer of the genetic elements controlling the $f^{+}$transfer factor alters the susceptibility of the $\mathrm{K} I 2 \mathrm{~F}^{+}$recipient strain to the MS 2 phage, irrespective of whether the $f^{+}$or the $f^{-}$transfer factor is actually responsible for transferring this determinant. The position was sometimes clarified by examining a number of the $\mathrm{K} / 2 \mathrm{~F}^{+}$colonies that had received the determinant. If some were susceptible to lysis by the MS 2 phage and some were not, it was inferred that an $\mathrm{fi}^{-}$transfer factor was responsible for mobili- 
zing the determinant. If none of them were lysed, it was assumed that an $f^{+}$factor was responsible although the presence of an $f^{-}$factor was not thereby excluded.

To obtain further information on the specificity of the relationship existing between transfer factors and determinants, I7 nonpathogenic strains of Escherichia coli isolated from the faeces of 17 pigs in different herds were examined. Tc was the only known transmissible character they possessed. The transfer factors in ten of them were $f^{-}$and in the remaining seven were $f i^{+}$. All 17 mobilized SmSu from $\mathrm{K}_{2} 2 \mathrm{~F}^{-} \mathrm{SmSu}^{+}$ (H I2I) and I 2, $7 \mathrm{fi}^{-}$and $5 \mathrm{fi}^{+}$, mobilized SmSu and Col from в ${ }_{65} \mathrm{SmSu}^{+} \mathrm{Col}^{+}$. Ten, five $f^{-}$and five $f^{+}$, mobilized Hly from K I2 $\mathrm{F}^{-} \mathrm{Hly}^{+}$(P IO2) and four, all $f^{+}$, mobilized it from P IO2.

Table 3. Classification of the transfer factor-bearing strains of Escherichia coli isolated from pigs, cattle and human beings according to the ability of their transfer factors to mobilize determinants

\begin{tabular}{|c|c|c|c|c|c|c|c|c|c|c|c|c|c|}
\hline & & & & & & bility to & mobilize & & & & & & \\
\hline & & & $\mathrm{SmSu}$ & from: & & & & & ic from & & Hly fr & rom: & \\
\hline $\begin{array}{l}\text { Identification } \\
\text { of strains }\end{array}$ & $\begin{array}{l}\mathrm{K}_{12} \mathrm{~F}^{-} \\
\mathrm{SmSu}^{+} \\
(\mathrm{H} I 2 \mathrm{I})\end{array}$ & $\begin{array}{c}\mathrm{B} \mathrm{I}^{65} \\
\mathrm{SmSu}^{+} \\
\mathrm{Col}^{+}\end{array}$ & $\begin{array}{c}\mathrm{K} I 2 \mathrm{~F}^{-} \\
\mathrm{SmSu}^{+} \\
(\mathrm{B} I 65) \\
\mathrm{Tc}^{+} \\
(\mathrm{H} I 20)\end{array}$ & $\begin{array}{c}\mathrm{H} \mathbf{1 2 I} \\
\mathrm{SmSu}^{+} \\
\mathrm{T}^{+}\end{array}$ & $\begin{array}{l}\mathrm{RT} 727 \\
\mathrm{SmSu}^{+}\end{array}$ & $\begin{array}{l}\text { B } 150 \\
\text { SmSu }^{+}\end{array}$ & $\begin{array}{c}\text { Col } \\
\text { from: } \\
\text { B 165 } \\
\mathrm{SmSu}^{+} \\
\mathrm{Col}^{+}\end{array}$ & $\begin{array}{c}\mathrm{K} I 2 \mathrm{~F}^{-} \\
\mathrm{SmSu}^{+} \\
(\mathrm{B} \mathbf{1 6 5}) \\
\mathrm{Tc}^{+} \\
(\mathrm{H} I 20)\end{array}$ & $\begin{array}{r}\mathrm{H} 120 \\
\mathrm{Tc}^{+}\end{array}$ & $\begin{array}{c}\text { H I 21 } \\
\mathrm{SmSu}^{+} \\
\mathrm{Tc}^{+}\end{array}$ & $\begin{array}{l}\overbrace{\mathrm{K} 12 \mathrm{~F}^{-}} \\
\mathrm{Hly}^{+} \\
(\mathrm{PIO2})\end{array}$ & $\begin{array}{l}\text { PIO2 } \\
\text { Hly }^{+}\end{array}$ & $\begin{array}{c}f i \text { character } \\
\text { of } \\
\text { transfer } \\
\text { factors }\end{array}$ \\
\hline H 89 & + & - & - & - & - & - & - & - & - & - & - & - & + \\
\hline P 275 & + & - & - & - & - & - & - & - & - & - & + & - & + \\
\hline P 280 & + & - & - & + & - & - & - & - & - & - & + & - & + and - \\
\hline $\mathrm{P}_{3} \mathrm{O}_{3}$ & + & + & - & - & - & - & - & - & - & - & - & - & - \\
\hline B 107 & + & - & + & - & - & - & - & + & - & - & + & - & - \\
\hline В 89, В I 48 & + & + & - & - & - & - & + & + & + & - & + & - & Both + and - \\
\hline $\mathrm{H} 92$ & + & + & + & - & - & - & + & + & + & - & + & - & + \\
\hline P 284, P 288, P 289 & + & + & + & + & + & + & + & + & - & - & - & - & - \\
\hline P276 & + & + & + & + & + & - & + & + & + & - & - & - & - \\
\hline B 105, в 149 & + & + & + & + & - & - & + & + & + & - & + & + & Both + and - \\
\hline B 167 & + & + & + & + & + & + & + & + & + & + & + & - & + and - \\
\hline H I00, H I IO & + & + & + & + & + & + & + & + & + & - & + & + & Both + and - \\
\hline KI2 $\mathbf{F}^{+*}$ & + & + & + & + & - & - & + & + & + & + & + & + & . \\
\hline KI2 $\mathbf{F}^{-}(\mathrm{P} 275)^{*}$ & + & - & - & + & - & - & - & - & - & - & + & + & . \\
\hline
\end{tabular}

$f$ : Fertility inhibition. For other abbreviations see Table 2.

* Included for comparison with the 20 wild transfer factor-containing strains; K $12 \mathrm{~F}^{-}$(P 275) contains the transfer factor obtained from the wild strain, $\mathbf{P} 275$.

Transfer factors in nonpathogenic $\alpha$-haemolytic strains of Escherichia coli of porcine origin

The properties of transfer factors in $\alpha$-haemolytic strains of Escherichia coli isolated from the faeces of 33 healthy animals in different herds are shown in Table 4 ; they did not belong to serotypes enteropathogenic for pigs. None of them possessed $\mathrm{R}$ factors, Ent were colicinogenic or carried phages or produced K 88 antigen. Transfer factors that mobilized resistance determinants were found in all ten strains that were shown to possess transmissible Hly but in only five of the 23 strains that were not. It is noteworthy that the transfer factors in three of these five strains mobilized Hly from $\mathrm{K} 2 \mathrm{~F}^{-} \mathrm{Hly}^{+}$(P IO2) yet haemolysin production in the three strains themselves was not shown to be transmissible. 
The incidence of transfer factors in enteropathogenic strains of Escherichia coli of porcine origin

The results of examining 97 porcine enterpathogenic strains of Escherichia coli for transfer factors are summarized in Table 5. The determinant donor strains were chosen from those studied previously as probably being the most useful for differentiating the transfer factors possessed by those 97 strains. The latter had been isolated from

Table 4. Transfer factors in nonpathogenic $\alpha$-haemolytic strains of Escherichia coli of porcine origin

\begin{tabular}{|c|c|c|c|c|c|c|c|c|c|}
\hline \multirow{4}{*}{$\begin{array}{c}\text { Trans- } \\
\text { missibility } \\
\text { of Hly }\end{array}$} & \multirow[b]{4}{*}{$\begin{array}{l}\text { No. of } \\
\text { strains }\end{array}$} & \multicolumn{6}{|c|}{ No, with transfer factors that mobilized } & & \\
\hline & & \multicolumn{3}{|c|}{ SmSu from } & \multirow{3}{*}{$\begin{array}{c}\mathrm{Tc} \\
\text { from: } \\
\text { H r } 20 \\
\mathrm{Tc}^{+}\end{array}$} & \multicolumn{2}{|c|}{ Hly from } & \multirow{2}{*}{\multicolumn{2}{|c|}{$\begin{array}{l}f i \text { character of } \\
\text { transfer factors }\end{array}$}} \\
\hline & & \multirow{2}{*}{$\begin{array}{l}\text { No. with } \\
\text { transfer } \\
\text { factors }\end{array}$} & \multirow{2}{*}{$\begin{array}{l}\mathrm{K} \mathbf{I} 2 \mathrm{~F}^{-} \\
\mathrm{SmSu}^{+} \\
\left(\begin{array}{lll}\mathrm{H} & \mathbf{1} & 2 \mathrm{I}\end{array}\right)\end{array}$} & \multirow{2}{*}{$\begin{array}{c}\text { B I65 } \\
\mathrm{SmSu}^{+} \\
\mathrm{Col}^{+}\end{array}$} & & \multirow{2}{*}{$\begin{array}{c}\text { K I } 2 \mathrm{~F}^{-} \\
\mathrm{Hly}^{+} \\
(\mathrm{P} \text { IO2) }\end{array}$} & \multirow[b]{2}{*}{$\begin{array}{l}\text { PIO2 } \\
\text { Hly }\end{array}$} & & \\
\hline & & & & & & & & $f^{+}$ & $f^{-}$ \\
\hline+ & IO & IO & IO & 9 & I & N.T. & N.T. & 2 & 8 \\
\hline- & 23 & 5 & 5 & 4 & I & 3 & 2 & 0 & $2^{*}$ \\
\hline
\end{tabular}

Table 5. The incidence and character of transfer factors in enteropathogenic strains of Escherichia coli of porcine origin

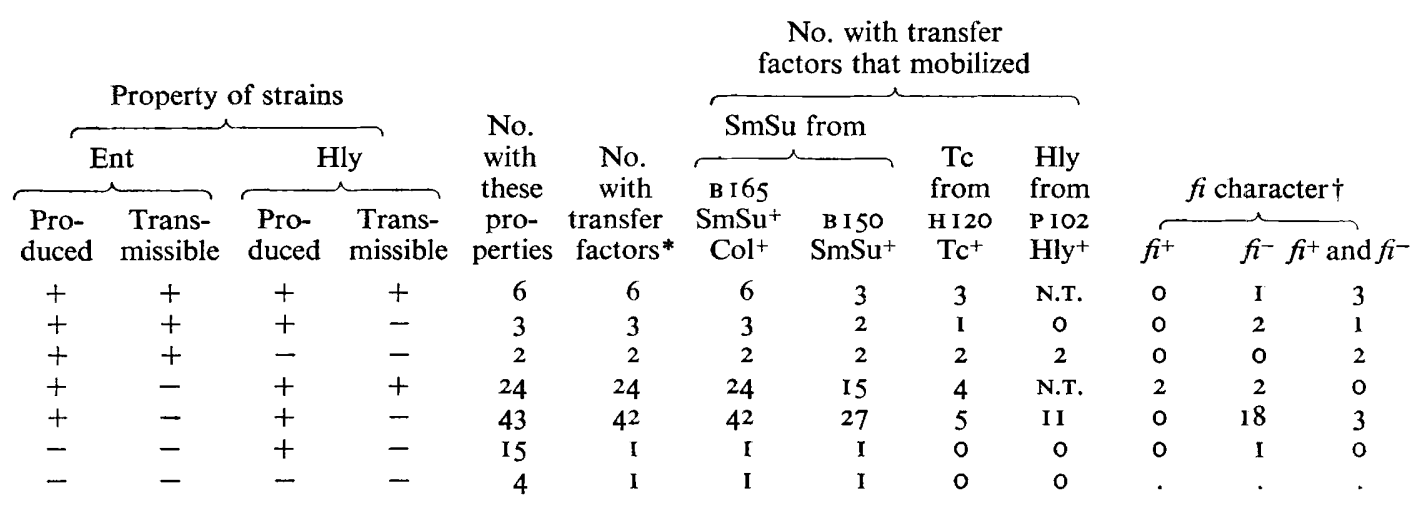

Forty-one of the enterotoxigenic strains possessed K 88 antigen; 56 did not.

* Identified by their ability to mobilize determinants.

$\dagger$ Not all the strains were tested. N.T. = Not tested.

different outbreaks of diarrhoea or oedema disease under conditions strongly indicating that they were playing an aetiological role. None of them possessed $\mathrm{R}$ factors, or transmissible Col. They all belonged to antigenic types generally accepted as being enteropathogenic for pigs, $4 \mathrm{I}$ to types that possessed the $\mathrm{K} 88$ antigen, types $08: \mathrm{K} 87$, $88 \mathrm{ab}$ (4 strains), $08: \mathrm{K} 87,88$ ac (I I strains), $045: \mathrm{K}$ ?, $88 \mathrm{ac}$ (4 strains), O I $4 \mathrm{I}: \mathrm{K} 85 \mathrm{ab}$, $88 \mathrm{ab}$ (4 strains), o I $47: \mathrm{K} 89,88 \mathrm{ac}$ ( 5 strains) and o I $49: \mathrm{K} 9 \mathrm{I}, 88 \mathrm{ac}$ ( 13 strains) and 56 to types that did not possess this antigen, types 09:K9 ( 2 strains), 045:K? (4 strains), o $138: \mathrm{K} 8 \mathrm{I}$ (I7 strains), o139:K82 (I9 strains), oI4I:K $85 \mathrm{ab} \leftrightarrow \mathrm{ac}$ (6 strains) and O I $4 \mathrm{I}: \mathrm{K} 85$ ac ( 8 strains). The $\mathrm{K} 88$ antigen was known to be transmissible in two of the 4I strains that possessed it; transmissibility was not examined in the remaining 39. 
All except one (P I02) of the 76 strains that produced enterotoxin and haemolysin, and the two strains that produced enterotoxin only, possessed transfer factors that could mobilize $\mathrm{SmSu}$ in B ${ }_{6} 65 \mathrm{SmSu}^{+} \mathrm{Col}^{+}$; most also mobilized this determinant in B I $50 \mathrm{SmSu}^{+}$but only a few mobilized Tc in H I $20 \mathrm{Tc}^{+}$. In 46 of these strains, haemolysin production was not found to be transmissible, yet I I of the 46 mobilized Hly from $\mathrm{P}$ I02 $\mathrm{Hly}^{+}$. No difference was detected between the transfer factors in the 4I enterotoxigenic strains that possessed the $\mathrm{K} 88$ antigen and those in the 37 that did not, either in their mobilizing ability or in their $f i$ character. In contrast to the enterotoxigenic strains, no transfer factors were detected in $\mathrm{I}_{4}$ of the $\mathrm{I}_{5} \alpha$-haemolytic strains that did not produce enterotoxin or in three of the four strains that produced neither enterotoxin or haemolysin; they had been tested with the good determinant donor strain $\mathrm{K} \mathrm{I}_{2} \mathrm{~F}^{-} \mathrm{SmSu}^{+}$(H $12 \mathrm{I}$ ), as well as with the four strains referred to in Table 5. All these 19 nonenterotoxigenic strains belonged to antigenic types or $39: \mathrm{K} 82$ (I 5 strains) and $045: \mathrm{K}$ ? ( 4 strains), types that usually cause oedema disease, a disease in which enterotoxin is not aetiologically involved. Of a total of 19 o I $39: \mathrm{K} 82$ strains examined, only four produced enterotoxin; in all four it was transmissible.

Because the transfer factors in most of the enterotoxigenic strains illustrated in Table 5 were $f^{-}$although Smith \& Halls (1968) had reported the transfer factors concerned with Ent transmission to be $f^{+}$, the strains possessing a transmissible Ent were submitted to closer examination. Six of nine such strains (Table 5) were found to contain an $f^{+}$as well as an $f^{-}$transfer factor. During these examinations, a nontransfer factor-containing strain of Salmonella typhimurium was grown in mixed culture with Escherichia coli P 19, a nonhaemolytic 09:K9 strain possessing a transmissible Ent. Attempts to mobilize the determinants in three determinant donor strains with the transfer factors in 19 clones of $S$. typhimurium obtained from this mixed culture (Table 6), suggest that the S. typhimurium organisms had either received no transfer factors, one transfer factor or two transfer factors from P I9, one mobilizing Tc from

Table 6. The determinant mobilizing ability of clones of a strain of Salmonella typhimurium that had been grown in mixed culture with Escherichia coli PI9 Ent ${ }^{+}$

Ability of their transfer factors to mobilize

$\begin{array}{ccccc}\begin{array}{l}\text { No. of } \\ \text { clones }\end{array} & \text { Ent } & \begin{array}{c}\text { SmSu from } \\ \text { B I 50 SmSu }\end{array} & \begin{array}{c}\text { Tc from } \\ \text { H I } 20 \mathrm{Tc}^{+}\end{array} & \begin{array}{c}\text { Hly from } \\ \text { P I02 Hly }\end{array} \\ 5 & + & + & + & + \\ 5 & + & + & - & - \\ \text { I } & - & + & + & + \\ \text { I } & - & - & - & + \\ 7 & - & - & & -\end{array}$

H I 20 and Hly from P IO2 and the other mobilizing SmSu from B I50, this one being responsible for Ent transmission. This was confirmed by showing that the transfer factor that mobilized SmSu from B I 50 was $f^{-}$and would not mobilize Tc from H 20 or Hly from P I02; while the transfer factor that had mobilized Tc from H 120 would not mobilize SmSu from B I50 but it would mobilize Hly from P I02.

Likewise the transfer factor that mobilized Hly from $\mathrm{P} I 02$ would not mobilize $\mathrm{SmSu}$ from B I5O but it would mobilize Tc from H I20; this transfer factor was $f^{+}$. Although the $f^{-}$transfer factor appeared to be responsible for Ent transmissions, its relationship 
with Ent was not close because it was present in two of the $S$. typhimurium clones that were Ent $^{-}$.

Similar results to those described above were obtained in studies on another four Ent $^{+}$strains. In three of them, Hly as well as Ent was transmissible; in these three, the $f^{+}$transfer factor was responsible for Hly transfer. In contrast to these five strains, a sixth was found to possess only an $f^{-}$transfer factor which mobilized SmSu in B 150 but not Tc and Hly in $\mathrm{H} I 20$ and $\mathrm{P} I 02$ respectively.

The relationship between the transmission of different determinants from enterotoxigenic strains of porcine Escherichia coli

Because in the studies reported above the transfer factors responsible for Ent transmission were able to mobilize $\mathrm{SmSu}$, the $\mathrm{SmSu}$ resistance in 12 wild enterotoxigenic strains of Escherichia coli were transmitted to $E$. coli $\mathrm{F} \mathrm{I} \mathrm{I,} \mathrm{a} \mathrm{strain} \mathrm{containing}$ no transfer factors but able to receive Ent. E. coli $\mathrm{K}$ I $2 \mathrm{~F}^{-}$, although a good recipient of Ent, was not used for this purpose because it is not easy to identify Ent ${ }^{+}$organisms of this strain (Smith \& Halls, I 968). Single and pooled $\mathrm{SmSu}^{+}$colonies of F I I obtained from each of the 12 mixed cultures were examined for Ent; none was positive. Fiftythree cultures prepared from single or pooled colonies of F I I to which $\mathrm{SmSu}$, Tc or Hly had been transferred from B I5O SmSu,$+ \mathrm{HI} 20 \mathrm{Tc}^{+}$or P IO2 $\mathrm{Hly}^{+}$respectively by

Table 7. The distribution of determinants among 200 colonies of Escherichia coli FII that had been grown in mixed culture with E. coli $\mathrm{P} 233 \mathrm{Ent}^{+} \mathrm{Hly}^{+} \mathrm{NeO}^{+} \mathrm{Col}^{+} \mathrm{K}_{88}^{+}$

To obtain a high transfer rate, the mixed culture of $\mathbf{P} 233$ and the recipient strain FII was passaged twice in broth; each passaged broth culture was incubated for $24 \mathrm{~h}$.

$\begin{array}{cc}\text { Determinant } & \begin{array}{c}\text { No. of } \\ \text { colonies }\end{array} \\ \text { Col } & 90 \\ \text { Neo } & 89 \\ \text { Ent } & 89 \\ \text { Hly } & 51 \\ \text { K } 88 & 51 \\ & \text { I }\end{array}$

\begin{tabular}{|c|c|c|c|c|c|}
\hline \multicolumn{5}{|c|}{ Determinant pattern } & \\
\hline Col & $\mathrm{Neo}$ & Ent & Hly & $\mathrm{K} 88$ & \\
\hline+ & + & + & + & - & 34 \\
\hline+ & + & + & - & - & 17 \\
\hline+ & + & - & + & - & I 6 \\
\hline+ & + & - & - & - & 18 \\
\hline+ & - & - & - & - & 4 \\
\hline- & + & - & - & - & 3 \\
\hline+ & + & - & + & + & I \\
\hline
\end{tabular}

the transfer factors possessed by a variety of enterotoxigenic pig strains of $E$. coli also yielded negative results when tested for Ent. In another experiment, $\mathrm{R}$ factors, single and multiple, coding for resistance to antibiotics such as tetracyclines, neomycin, chloramphenicol, streptomycin and sulphonamides were transmitted to $E$. coli $\mathrm{HI}$ from 30 enterotoxigenic $\alpha$-haemolytic pig strains, I 4 of which produced $\mathrm{K} 88$ antigen; $\mathrm{H}$ I was a human enteropathogen able to receive Ent. None of the 30 resulting antibiotic-resistant strains of $\mathrm{HI}$ was either $\mathrm{Ent}^{+}$, $\mathrm{Hly}^{+}$or $\mathrm{K} 88^{+}$. Hly, also, was found in 
only one of 12 strains of $\mathrm{K}_{2} 2 \mathrm{~F}^{-}$or FII to which Tc or SmSu had been transmitted from $\mathrm{HI} 20 \mathrm{Tc}^{+}$or B I50 SmSu${ }^{+}$by transfer factors possessed by haemolytic enterotoxigenic strains.

Absence of close linkage between Ent and Hly and between them and K 88, Col and neomycin resistance in a wild strain of Escherichia coli, P233, antigenic formula $08: \mathrm{K} 87,88 \mathrm{ac}$, is illustrated in Table 7 . At least two transfer factors were contained in P233, one $f^{+}$and the other $f^{-}$.

Transfer factors in strains of Escherichia coli enteropathogenic for human babies, lambs or calves

The results of examining strains of Escherichia coli isolated from different outbreaks of diarrhoea in human babies, lambs and calves for transfer factors are summarized in Table 8 . The human strains belonged to serotypes generally accepted as being enteropathogenic for babies; severe diarrhoea has been produced in calves and lambs by oral inoculation of the calf and lamb strains. None of the 28 strains was antibioticresistant or carried phages active against $E$. coli $\mathrm{K} I 2 \mathrm{~F}^{-}$. A few were colicinogenic and one, from a lamb, was haemolytic; none of these characters was found to be transmissible. The transfer factors in the human strains differed, as a group, from those found in the porcine enterotoxigenic strains in that only five of the 15 strains possessing them mobilized $\mathrm{SmSu}$ in B $165 \mathrm{SmSu}^{+} \mathrm{Col}^{+}$and only three mobilized it from в 150 $\mathrm{SmSu}^{+}$; nearly half of them, too, were $f^{+}$. The distribution of transfer factor-containing strains amongst the different antigenic types was 026 ( $\mathrm{I}$ of 2 strains examined), O55 ( 2 of 5), O I I (I of I), O I I9 ( 5 of 5), O I 25 (I of I), O I27 (O of I) and o I 28 (5 of 6).

Table 8. Transfer factors in strains of Escherichia coli enteropathogenic for human babies, lambs and calves

\begin{tabular}{|c|c|c|c|c|c|c|c|c|}
\hline \multirow{3}{*}{$\begin{array}{l}\text { Source } \\
\text { of } \\
\text { strains }\end{array}$} & \multirow{3}{*}{\multicolumn{2}{|c|}{$\begin{array}{c}\text { No. } \\
\text { with } \\
\text { transfer } \\
\text { No. factors* }\end{array}$}} & \multicolumn{3}{|c|}{ No. with transfer factors that mobilized } & \multirow{2}{*}{\multicolumn{3}{|c|}{$\begin{array}{c}f i t \text { character of } \\
\text { their transfer } \\
\text { factors }\end{array}$}} \\
\hline & & & \multicolumn{2}{|c|}{ SmSu from } & \multirow{2}{*}{$\begin{array}{l}\text { Tc from } \\
\text { H I } 20 \mathrm{Tc}^{+}\end{array}$} & & & \\
\hline & & & $\mathrm{KI}_{2} \mathrm{~F}^{-} \mathrm{SmSu}^{+}\left(\mathrm{H} \mathrm{I}_{2} \mathrm{I}\right)$ & B I $65 \mathrm{SmSu}^{+} \mathrm{Col}^{+}$ & & $\begin{array}{l}\text { Hly from } \\
\text { P IO2 Hly }\end{array}$ & $\mathrm{fi}^{+}$ & $f^{-}$ \\
\hline $\begin{array}{r}\text { Human } \\
\text { Babies }\end{array}$ & 21 & I 5 & 15 & 5 & 2 & 0 & 7 & 8 \\
\hline Lambs & 5 & I & I & I & 0 & I & $\mathbf{I}$ & 0 \\
\hline Calves & 2 & 2 & 2 & 2 & $\mathrm{I}$ & 0 & I & 0 \\
\hline
\end{tabular}

The incidence of strains of Escherichia coli in which colicine production was transmissible

Of 137 strains of Escherichia coli isolated from the faeces of unrelated healthy human beings, calves and pigs, $3 \mathrm{I}$ produced colicine active against $E$. coli $\mathrm{K} 12 \mathrm{~F}^{-}$. Its production in 10 of 20 tested strains was shown to be transmissible. Among 36 strains from healthy pigs, I I produced colicine: its production in 5 of 9 tested strains was transmissible. Of 22 I strains of $E$. coli enteropathogenic for pigs, 83 produced colicine; production in 7 of 36 tested strains was transmissible. 


\section{DISCUSSION}

The incidence of transfer factors, $33 \%$, amongst the 60 strains of Escherichia coli isolated from the faeces of healthy cattle, pigs and human beings, and selected because they were neither antibiotic-resistant nor produced colicine, haemolysin, K 88 antigen or porcine enterotoxin (characteristics that may be transmissible), was considerably higher than the $7 \%$ found by Lewis (1968) in 135 antibiotic-sensitive, noncolicineproducing strains of $E$. coli isolated from the general human population; it approached that in salmonellae (Anderson, 1968). One reason for this difference might be that Lewis used only one determinant donor strain whereas we used nine, one of which $\mathrm{K} \mathrm{I}_{2} \mathrm{~F}^{-} \mathrm{SmSu}^{+}$(H I2I), was particularly good. Results of the determinant mobilization tests were not always reproducible. The ability to detect the presence of a transfer factor within a cell was not simply a function either of the transfer factor itself or of the mobilizable determinant. It varied with the bacterial strain containing the transfer factor, the strain containing the determinant and that used as the final recipient. Mobilization was achieved most easily when all three strains were $\mathrm{K} \mathrm{I} 2$.

It seems likely, then, that the actual incidence of transfer factors in the 60 strains we examined was higher than $33 \%$. Apart from the technical difficulties in demonstrating transfer factors, it remains possible that some of the strains possessed transfer factors which would not mobilize any of the determinants in the nine determinant donor strains. One of the donor strains, $\mathrm{H} 120 \mathrm{Tc}^{+}$, possessed a transfer factor, also present in another donor strain derived from it, $\mathrm{KI}_{2} \mathrm{~F}^{-} \mathrm{SmSu}^{+}$(BI65) $\mathrm{Tc}^{+}$(H I2O), that would neither transmit the determinants in these two strains nor mobilize those in the other donor strains. This transfer factor was only detected by the fact that it inhibited the expression of $\mathrm{F}$ in $\mathrm{KI} 2 \mathrm{~F}^{+}$. Since it was not linked to the determinants in the two strains, it is more logical to regard it simply as unable to facilitate the transfer of these determinants rather than to suppose that it had lost the ability to do so, because it was defective (Cuzin \& Jacob, 1965).

At least two transfer factors were identified in"eight of the 20 strains tested on the basis of the fertility-inhibition $(f i)$ test. The $f i$ test only permits classification of transfer factors into two groups, $f^{+}$and $f^{-}$(Watanabe, 1963), and the presence of more than one $f^{+}$or more than one $f^{-}$transfer factor in the same bacterial cell cannot be readily detected.

Transfer factors that mobilized determinants for antibiotic resistance were found in only five of the 23 nonpathogenic strains of Escherichia coli whose $\alpha$-haemolysin production could not be shown to be be transmissible, an incidence no higher than that found in the 60 nonpathogenic strains that did not possess characters known to be transmissible. Since the transfer factors in all of the Io nonpathogenic strains whose haemolysin production was transmissible were able to mobilize these antibiotic resistance determinants, this is evidence that the haemolysin production in most of the 23 strains was really nontransmissible and not that its rate of transfer was too low to be detected by our methods. The transfer factors in three of the five strains which possessed them were able to mobilize Hly from the Hly ${ }^{+}$donor strains as did I I of the 44 porcine enteropathogenic strains whose haemolysin production was not shown to be transmissible. It is possible, then, that the genetic elements coding for haemolysin production in at least these 14 strains may not be located in plasmids at all but in the chromosome. In regard to the actual transfer factors involved in Hly transmission, 
those examined by Smith \& Halls (I967a) were $f i^{+}$. Examination of those in the ten nonpathogenic strains referred to above, however, revealed that some were $f^{+}$and some were $f i^{-}$.

All except one of the 78 porcine enterotoxigenic strains of Escherichia coli that did not possess $\mathrm{R}$ factors or transmissible Col possessed transfer factors that mobilized determinants from our donor strains. These transfer factors were known to be responsible in some of the strains for the transmission of $\mathrm{K} 88$, haemolysin production and enterotoxin production. It would be extremely difficult by the methods presently available to determine the exact extent to which these three properties were controlled by transmissible plasmids because they can be detected only if the rate of transfer is high. For the reasons given in the previous paragraph, it seems unlikely that the transfer factors in the 77 enterotoxigenic strains were principally concerned with Hly transmission, or with K 88 transmission, because 37 of them did not possess this antigen. It is possible, then, that the transfer factors were principally concerned with Ent transmission, thus implying that enterotoxin production in all the strains was controlled by transmissible plasmids. The observations on the $19 \alpha$-haemolytic strains of serotype o I39:K82, a serotype mainly incriminated in oedema disease rather than in diarrhoea, supported this view in that transfer factors could be demonstrated only in the four that produced enterotoxin.

As for the 20 nonpathogenic strains that possessed transfer factors, it was not unusual to find both $f^{+}$and $f i^{-}$transfer factors in the same enterotoxigenic strain. In the present work, both $f^{+}$and $f^{-}$transfer factors were found in the strains that had led Smith \& Halls (I968) to the erroneous conclusion that the factors mediating Ent transfer were $f^{+}$. It is probable that in their investigations the presence of the $f i^{+}$factor had masked that of the $f^{-}$factor transmitting Ent.

Even in the porcine strains shown to contain a transmissible Ent plasmid, the linkage between plasmid and transfer factor was not close. In clones of Escherichia coli F I I recovered after the mating with strain P 233 the Ent plasmid was not linked to any of the plasmids controlling the production of haemolysin, colicine and $\mathrm{K} 88$ antigen or neomycin resistance. These facts provide possible explanations for our failure to isolate $\mathrm{Ent}^{+}$recipient organisms from mating mixtures by selecting those that had received antibiotic resistance or Hly from donor strains that produced enterotoxin but whose enterotoxin production could not be shown to be transmissible by the usual procedure.

Amongst the strains enteropathogenic for animals other than pigs, the fact that only one of the five sheep strains contained transfer factors is taken as evidence that transmissible plasmids do not control any characteristic common to this kind of strain. The incidence of transfer factors in the 2 I human enteropathogenic strains was considerably higher than that in the comparable group of human nonpathogenic strains, $7 \mathrm{I} \%$ compared with $30 \%$. It may be that the human enteropathogens, as a group, possess characteristics that are controlled by transmissible plasmids.

We are grateful to Mr T. Humphrey and Miss Diane Poulton, Miss Carole Smith and Miss Marion White for their capable technical help. Our thanks are also due to Dr E.S. Anderson, Dr C. L. Gyles, Mrs Esther Johnson, Dr Elinor Meynell and Dr K. C. Sellers for help and assistance in various ways. We are pleased to acknowledge the financial help provided by the Agricultural Research Council and the Meat and Livestock Commission. 


\section{REFERENCES}

ANDERSON, E. S. (1965a). A rapid screening test for transfer factors in drug-sensitive Enterobacteriaceae. Nature, London 208, 1016-1017.

ANDERSON, E. S. (1965b). Origin of transferable drug-resistance factors in the Enterobacteriaceae. British Medical Journal ii, I289-I29I.

Anderson, E. S. (1968). The ecology of transferable drug resistance in the enterobacteria. Annual Review of Microbiology 22, 13I-I80.

Anderson, E. S. \& Lewis, M. J. (1965). Characterization of a transfer factor associated with drug resistance in Salmonella typhimurium. Nature, London 208, 843-849.

Cuzin, F. \& J $\mathrm{JCOB}_{\mathrm{B}}$, F. (1965). Analyse génétique fonctionnelle de l'episome sexuel d'Escherichia coli. Compte Rendu Hebdomadaire des Séances de l'Académie des Sciences, Paris 260, 2087-2090.

Davis, J. E., Strauss, J. H. Jun. \& Sinsheimer, R. L. (I96I). Bacteriophage MS 2 : another RNA phage. Science, New York 134, 1427.

LEwIS, M. J. (1968). Transferable drug resistance and other transferable agents in strains of Escherichia coli from two human populations. Lancet i, 1389-1393.

Smith, H. Williams (1963). The haemolysins of Escherichia coli. Journal of Pathology and Bacteriology $85,197-2$ II.

Smith, H. Williams \& Gyles, C. L. (1970). The relationship between different transmissible plasmids introduced by $\mathrm{F}$ into the same strain of Escherichia coli $\mathrm{K} 12$. Journal of General Microbiology 62, 277-285.

Smith, H. Williams \& Halls, S. (1967a). The transmissible nature of the genetic factor in Escherichia coli that controls haemolysin production. Journal of General Microbiology 47, I53-161.

Smith, H. Williams \& Halls, S. (I967b). Observations by the ligated intestinal segment and oral inoculation methods on Escherichia coli infections in pigs, calves, lambs and rabbits. Journal of Pathology and Bacteriology 93, 499-529.

Smith, H. Williams \& Halls, S. (1968). The transmissible nature of the genetic factor in Escherichia coli that controls enterotoxin production. Journal of General Microbiology 52, 319-334.

Watanabe, T. (1963). Infective heredity of multiple drug resistance in bacteria. Bacteriological Reviews 27, 87-II5. 